\title{
STRESS TOLERANT RICE AND ON-FARM SEED PRODUCTION ENSURE FOOD SECURITY AND LIVELIHOOD TO SMALL AND MARGINAL FARMERS OF SUNDARBANS (INDIAN SITE)
}

\author{
K. Chattopadhyay ${ }^{1}$, S. Gayan ${ }^{1}$, I. Mondal ${ }^{2}$, S.K. Mishra ${ }^{1}$, A.K. Mukherjee ${ }^{1}$ \\ J.N. Reddy ${ }^{1}$, B.C. Marndi ${ }^{1}$ and R.K. Sarkar ${ }^{1 *}$
}

${ }^{1}$ ICAR- National Rice Research Institute, Cuttack-753006, Odisha, India

${ }^{2}$ Vidyasagar University, Paschim Medinipur, West Bengal-721102, India

\begin{abstract}
Natural calamities have adverse effects on the life of marginal and small farmer practicing rice cultivation in Sundarban areas. Through discussion and questionnaires opinion of farmers were obtained that was applied to mitigate the problem of rice cultivation. Rice varieties tolerant to stagnant flooding, submergence and salinity had great promise to improve food security and livelihoods of the poor farmers of Sundarban area. The study revealed that small and marginal farmers accepted the new varieties very readily if seeds were produced locally. Informal seed systems had better promise for small and marginal farmers live in fragile ecosystem of Sundarban.
\end{abstract}

Keywords: Climate Change, Food Security, Livelihood, Sundarban

\section{INTRODUCTION}

The area of the Sundarbans is decreasing fast due to various reasons starting from increasing human population to the effect of other edaphic factors such as flooding, heavy siltation and salinity due to the control water flow at upper embankment of the rivers, beach erosion and cyclonic storm surges. Poorest of the poor live in these areas and always expose to natural calamities (Ghosh et al., 2015). Mangroves forest is disappearing at alarming rate of $2 \%$ per year and the situation is alarming over alarming (Aziz and Paul, 2015). 70\% of people in Sundarbans depend on agriculture. Rice is mainly cultivated once in a year during wet season (Sarkar and Ray, 2016). So, increasing rice productivity along with work opportunity among the poor farmers may help to preserve the vulnerable mangroves forest and other life forms in the region. The scenario is denigrated further due to climate change (Dasgupta et al., 2016). Farming community especially those are nature dependent is mostly

\footnotetext{
*Corresponding author: rksarkarcrri@gmail.com
} 
vulnerable due to climate change as they grow crops in an open environmental condition with all sort of vagaries (Bastakoti et al., 2014). In this investigation we tried to understand the problem of rice cultivation through discussion and questionnaires', imparted training on different aspects of rice cultivation techniques, rice seed production and last of all 'seeing is believable', several demonstrations were done with stress tolerant rice cultivars to create awareness among farming community of the region. The main objective of the investigation was to improve food security and livelihood among the small and marginal farmers of the Sundarbans area.

\section{MATERIALS AND METHODS}

\section{Study site, climate and rice ecology}

The study areas were the both Eastern and Western Sundarbans of Indian site that was situated between $22^{\circ}$ to $22^{\circ}-56{ }^{\prime} \mathrm{N}$ and $88^{\circ}-41^{\prime}$ to $89^{\circ}-23^{\prime} \mathrm{E}$. Demonstrations of climate resilient rice varieties were done in five blocks of Sundarban region, namely, Sandeshkhali-I and Hingalganj (Eastern part) of North 24 Parganas and Gosaba, Basanti and Patharpratima (Western part) of South 24 Parganas. Among the five blocks Patharpratima is the part of the Sundarban Biosphere Reserve.

\section{Study site and Interview and focus group discussion (FGD)}

Both quantitative (interview schedule) and qualitative (FGD) features were used to know about soil salinity, water logging and submergence and their impact on rice. The survey targeted 99 farmers in two villages of Sundarbans of North 24 Parganas. The sample size of Chhoto Sehara, Sandeshkhali-I was 49 and of Kumirmari, Hingalganj was 50. Interview was designed to capture relevant data pertaining to rice cultivation. The secondary data were collected from published data sources. FGD was done in all the five blocks of study area. FGD was initiated on 2012 winter season after the harvest of Wet season crops. Thereafter during the years of 2013-14, 2014-15 and 2015-16 several meetings, training and demonstrations of rice cultivars were done. Farmers were invited at cultivation site to judge the performances of varieties. During harvest a general survey was done about the performances of rice varieties and opinion of the farmers was sought for about a variety related to the acceptance of it by him / her.

\section{Testing of rice varieties}

During 2013 wet season where occasional salinity and stagnant flooding (up to $45 \mathrm{~cm}$ depth) were major stresses, three released rice varieties such as CR Dhan 402, CR Dhan 403 and CR Dhan 406 were grown along with one farmers' variety such as SR 26B. Numbers of farmers were six and each farmer was considered as one replication. Seeing the performances of CR Dhan 403 and CR Dhan 406 respectively, 23 and 13 demonstrations were made during the year 2014 with other local cultivars in different locations. Varshadhan, Swarna-Sub1 and Savitri-Sub1 were grown along 
with the local cultivars in 18, 13 and 6 sites, respectively during the year 2014 and 2015 in stagnant flooding $(40-70 \mathrm{~cm}$ depth) and submergence prone areas. Twice in a month two physical parameters such as water depth and level of salinity were noted.

\section{Output \& outcome, Failures, and impact}

We provided three hundred and thirty $\mathrm{Kg}$ of seeds of different stress tolerant rice varieties to farmers at initial level. Two $\mathrm{Kg}$ of seeds were given to each farmer. Characteristics of seeds were explained to farmers so that they can cultivate the variety at appropriate ecology. Outcome of the programme was measured based on the intention of the farmers to grow stress tolerant rice varieties in the subsequent season. Impacts of the programmes outcome were measured based on broader changes within the community that took interest in the production of seeds of stress tolerant rice cultivars and selling of rice as seeds from farmer to farmer.

\section{Statistical analysis}

Ranking of each parameter was made based on their Weighted Cumulative Score (WCS) Yu et al. (2016). To demonstrate significant differences between stress tolerant rice variety and farmers' variety paired t-test was done. WCS of the two parameters such as preference of rice cultivars and problems of rice cultivation were first normalized taking highest WCS as ' 1 ' and accordingly other data were also changed. Each village data was normalized separately taking highest WCS as '1' to give the similar credence of WCS. Spearman rank correlation was done to test the association of the farmers' perception between two villages. Statistical analysis was done using either IBM SPSS Statistics (version 20) software or EZR.R (version 2.40) (Kanda, 2013).

\section{RESULTS}

\section{Land holding capacity, economic status, education and purpose of rice cultivation}

Land-holding capacity of most of the farmer was below 1 ha (Fig. 1). Most of the farmers of Choto Sehera were below poverty line (BPL) category (79.6\%), whereas at Kumirmari $4 \%$ of farmers were BPL category. The education status of the farmers did not vary much between the two villages. Primary objective of rice cultivation was to provide food to the family members (subsistence type). Ploughing method differed greatly in two villages (Fig. 1). Rice cultivation mainly depended on rainfall. Shallow and Deep-tube wells were available in the both the villages but only $46.9 \%$ and $42 \%$ of the farmers of Choto Sehera and Kumirmari, respectively could utilize such facilities during the emergency. 


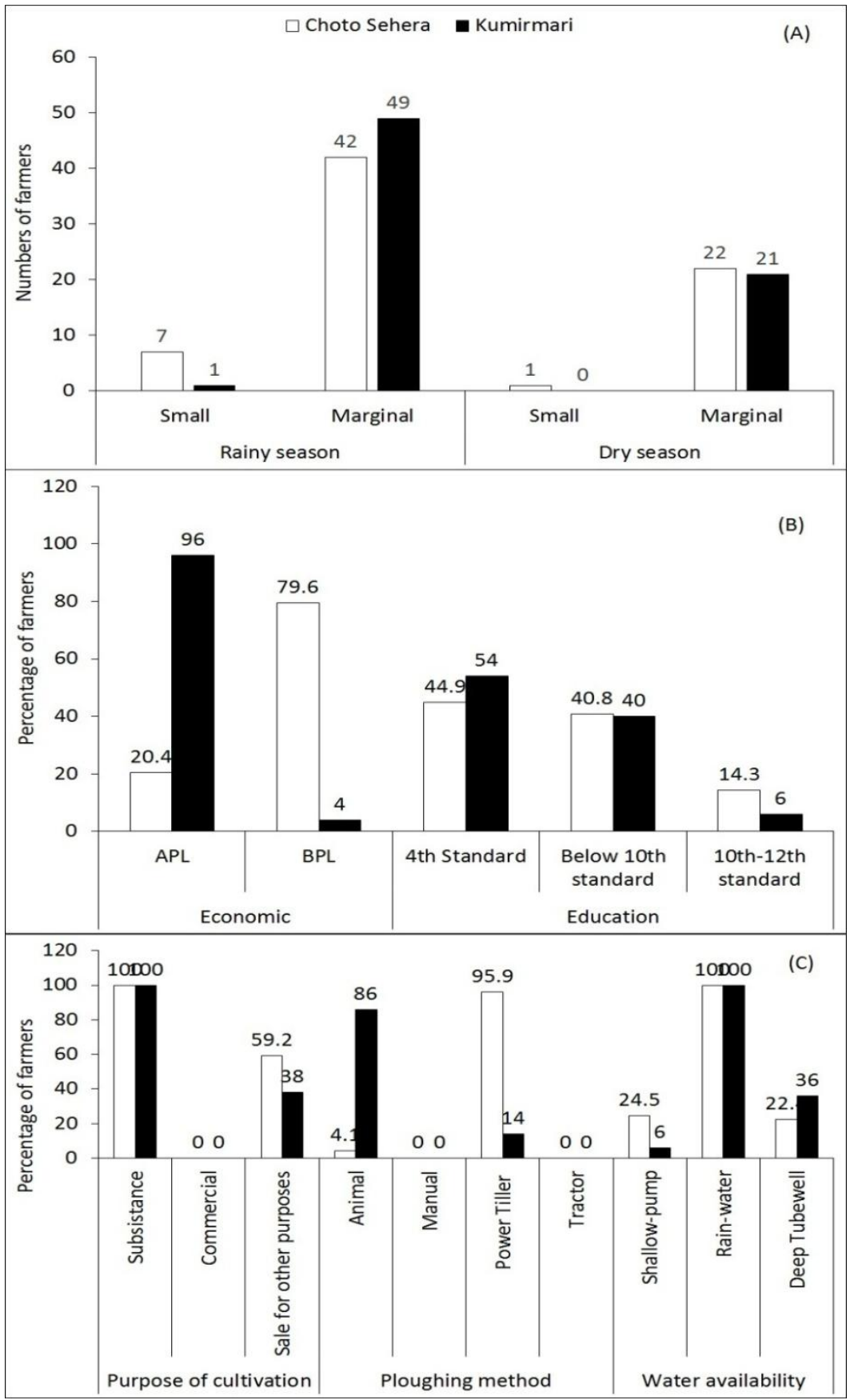

Figure 1. Land holding capacity (A), economic status (B), education and purpose of rice cultivation $(C)$ in two villages of Sundarbans. 


\section{Perception of farmers about problems in rice cultivation}

Rice cultivation that is also under stressful environment is challenging in many respects (Fig. 2). Perception of farmers on problem of rice cultivation between the villages did not differ much. Spearman correlation analysis showed significant association at $\mathrm{p}<0.05\left(r h o=0.461^{*}\right)$. Selling of paddy below minimum support price (MSP) and flooding were the most predominant problems followed by erratic rainfall, unavailability of quality seeds and infestation of insects and pests at Choto Sehera whereas flooding, erratic rainfall, unavailability of quality seeds and lack of enough pesticides and availability of fertilizers at right time were predominant factors hindering rice cultivation at Kumirmari.

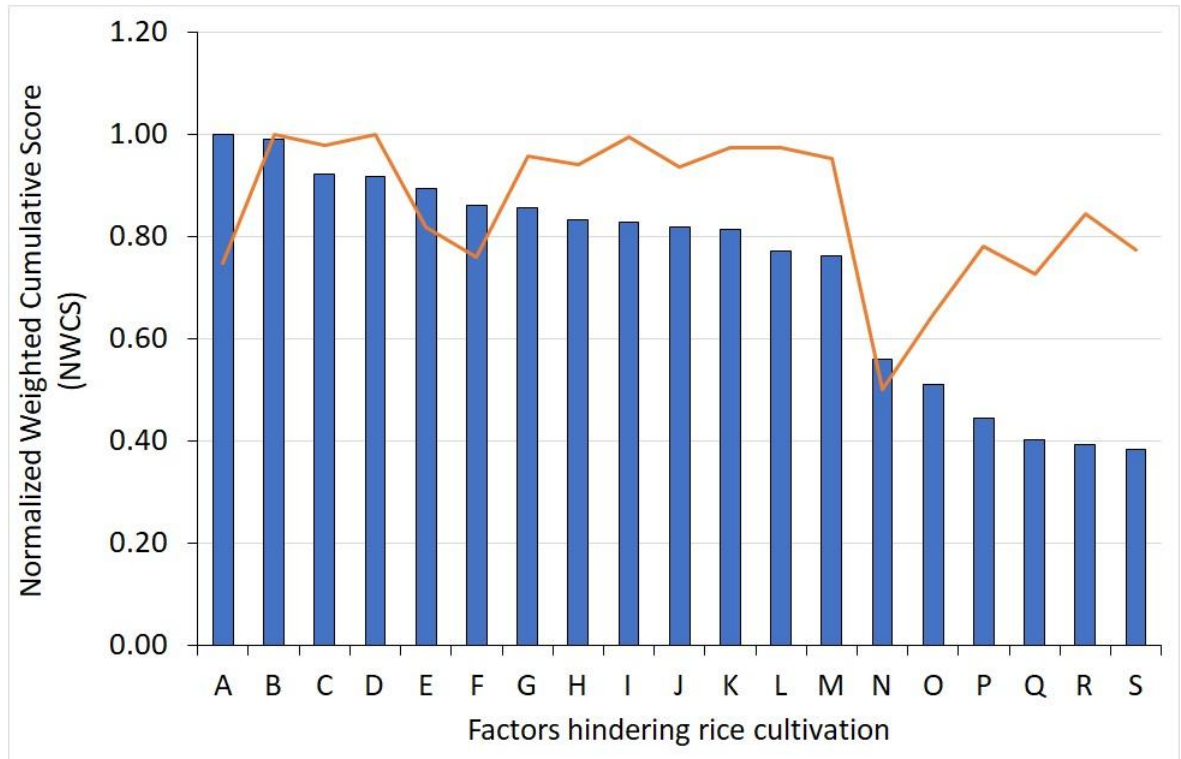

Figure 2. Perception of farmers on problematic issues in rice cultivation. A. Sale of paddy below minimum support price (MSP) fixed by govt, B. Flood and submergence after heavy rain, C. Erratic rainfall in rainfed areas, D. Unavailability of quality seeds in time, E. Infestation of insects and pests, F. Infestation of diseases, G. Lack of proper technical knowledge and skill in rice farming, H. Unavailability of labour during rice cropping season, I. Unavailability of enough pesticides and fertilizers, J. High cost of farm inputs (like seeds, fertilizers, pesticides and labour), K. Crop damage due to drought or water scarcity, L. Poor economic condition of self/ farmers, M. Lack of irrigation facility, N. 'Illegal practices and bribes by govt. officials for providing services, loans and subsidy etc., O. Poor farmersextension workers linkage, P. Unavailability of enough nos. of farm implements/machineries, Q. Unavailability of references materials for farmers, R. Lack of knowledge in handling of farm machineries, S. Incompatibility of farm machineries in our farming situation. 


\section{Farmers' preference in selection of rice varieties}

The choices of farmers in both the villages were more or less similar (Fig. 3). Spearman correlation analysis showed highly significant association at $\mathrm{p}<0.001$ (rho $=0.852 * * *$ ). If importance and moderately importance are taken into one unit more than $80 \%$ farmers of both the villages gave importance on 7 items among the 15 items. These were high yield (productivity) $>$ resistance to disease and pests $=$ tolerance to flood and submergence > tolerance to occasional drought or water shortage $>$ easily marketable $>$ tolerance to salinity $=$ bold grain quality. Early duration and fine grain quality came next with normalised score of 0.75 . Based on the interview, group discussion and prevalent abiotic stresses rice varieties were chosen for demonstration (Table 1).

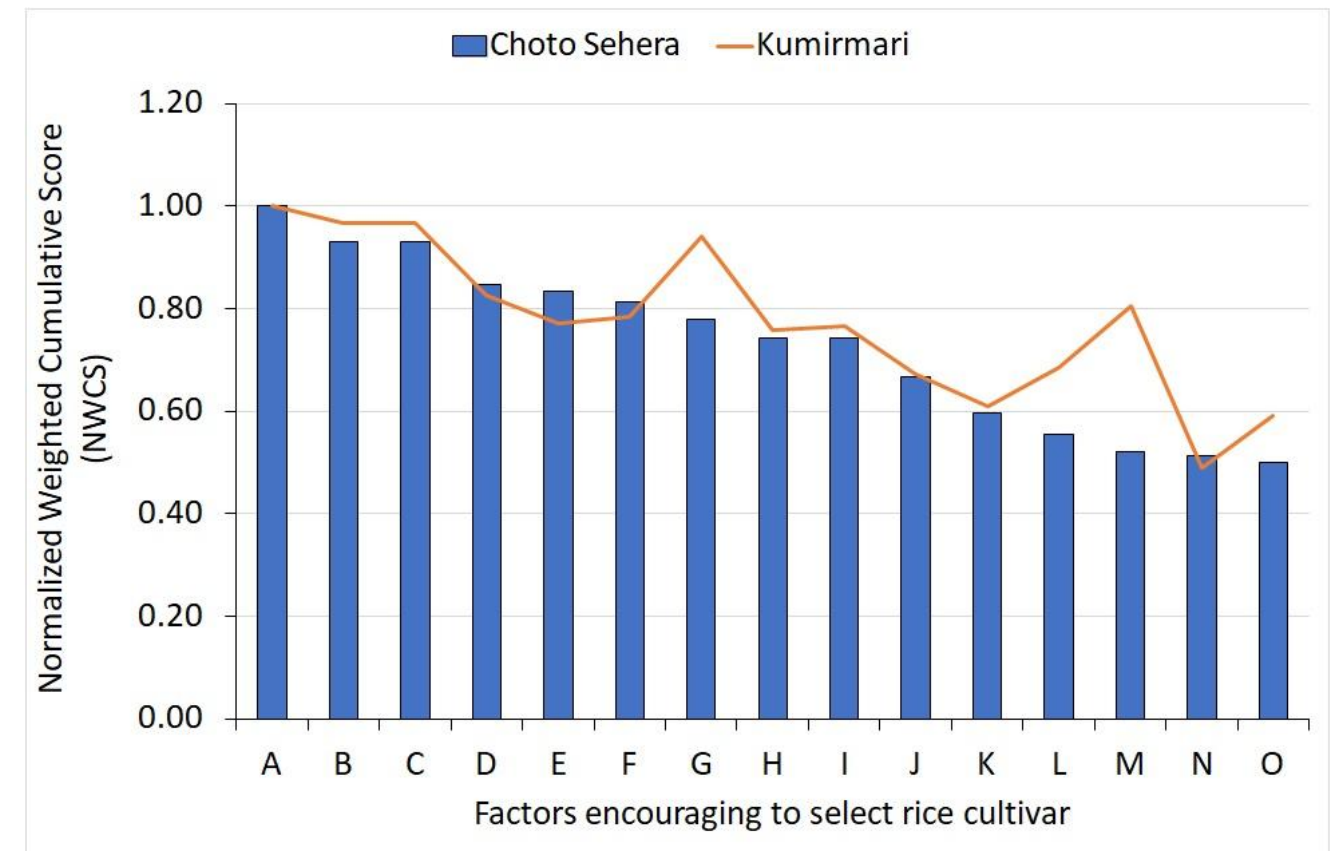

Figure 3. Criteria to prefer rice varieties by the farmers of two villages of Sundarbans area. [A - High yield (productivity), B - Resistance to disease and pests, C - Tolerance to occasional drought or water shortage, D - Tolerance to flood and submergence, E - Tolerance to salinity, F - Good milling quality of paddy, G - Good cooking quality, H - Good quality paddy straw, I - Early duration of maturity, $\mathrm{J}$ - Easy to prepare value added products (Raw rice/ Parboiled rice / Watered rice / Expanded rice / flattened rice / Puffed rice), K - Easily marketable, L White coloured grain, M - Fine grain quality, N - Bold grain quality, O - Response to low dose of fertilizer/ organic manure] 
Table 1. Rice varieties chosen for demonstration based on interview and group discussion.

\begin{tabular}{|c|c|c|c|c|c|}
\hline Variety & $\begin{array}{c}\text { Duration } \\
\text { (days) }\end{array}$ & $\begin{array}{c}\text { Height } \\
(\mathrm{cm})\end{array}$ & $\begin{array}{c}\text { Interactions } \\
\text { with disease \& } \\
\text { pests }\end{array}$ & $\begin{array}{c}\text { Productivity } \\
\left(\mathrm{t} \mathrm{ha}^{-1}\right)\end{array}$ & Remarks \\
\hline $\begin{array}{l}\text { Varshadhan } \\
\text { (CRLC 899) }\end{array}$ & 160 & 150 & $\begin{array}{l}\text { Tolerance to } \\
\text { neck blast, } \\
\text { BLB, sheath rot } \\
\text { and WBPH }\end{array}$ & 4.0 & $\begin{array}{l}\text { Can tolerate up to } 75 \mathrm{~cm} \\
\text { depth of water; long bold } \\
\text { grain }\end{array}$ \\
\hline $\begin{array}{l}\text { Swarna-Sub1 } \\
\text { (CR 2539-1) }\end{array}$ & 143 & 100 & -------------- & 5.5 & $\begin{array}{l}\text { Tolerant to submergence; } \\
\text { medium slender grain }\end{array}$ \\
\hline Savitri-Sub1 & 155 & 120 & $\begin{array}{c}\text { Tolerant to } \\
\text { blast and sheet } \\
\text { blight }\end{array}$ & 5.5 & $\begin{array}{l}\text { Tolerant to submergence; } \\
\text { short bold grain }\end{array}$ \\
\hline $\begin{array}{l}\text { Luna Suvarna } \\
\text { (CR Dhna 403) }\end{array}$ & 150 & 135 & --------------- & 4.0 & $\begin{array}{l}\text { Tolerant to salinity }(5.0-8.0 \\
\mathrm{dS} / \mathrm{m}) \text { and } \mathrm{SF} \text { up to } 45 \mathrm{~cm} \text {; } \\
\text { medium slender grain }\end{array}$ \\
\hline $\begin{array}{l}\text { Luna Sampad } \\
\text { (CR Dhan 402) }\end{array}$ & 140 & 130 & $\begin{array}{l}\text { Resistance to } \\
\text { blast }\end{array}$ & 4.2 & $\begin{array}{l}\text { Tolerant to salinity }(5.0-8.0 \\
\text { dS/m) and SF up to } 45 \mathrm{~cm} \text {; } \\
\text { medium bold grain }\end{array}$ \\
\hline $\begin{array}{c}\text { Luna Barial } \\
\text { (CR Dhan 406) }\end{array}$ & 155 & 120 & $\begin{array}{l}\text { Tolerant to } \\
\text { YSB }\end{array}$ & 3.9 & $\begin{array}{l}\text { Tolerant to salinity }(5.0-8.0 \\
\mathrm{dS} / \mathrm{m}) \text { and } \mathrm{SF} \text { up to } 45 \mathrm{~cm} \text {; } \\
\text { short bold grain }\end{array}$ \\
\hline $\begin{array}{l}\text { Luna Sankhi } \\
\text { (CR Dhan 405) }\end{array}$ & 120 & 110 & ------------- & 4.6 & $\begin{array}{l}\text { Tolerant to salinity }(5.0-8.0 \\
\mathrm{d} / \mathrm{m}) ; \text { medium slender } \\
\text { grain, suitable for dry } \\
\text { season. }\end{array}$ \\
\hline
\end{tabular}

\section{Categorization of land on the basis of salinity, drought and flooding}

Categorization of land based on prevalent abiotic stresses revealed that abiotic stresses such as drought, salinity, stagnant flooding and submergence were predominant in both the villages (Fig. 4). Stagnant flooding (31\%) and salinity (25\%) were prevalent at Choto Sehera whereas salinity (58\%) and submergence (21\%) were more dominant at Kumirmari. Categorization of water-stagnation revealed that medium depth $(50 \mathrm{~cm})$ stagnant flooding was more predominance, followed by deep (>50 to $90 \mathrm{~cm}$ ) and shallow water stagnation (up to $30 \mathrm{~cm}$ ). 


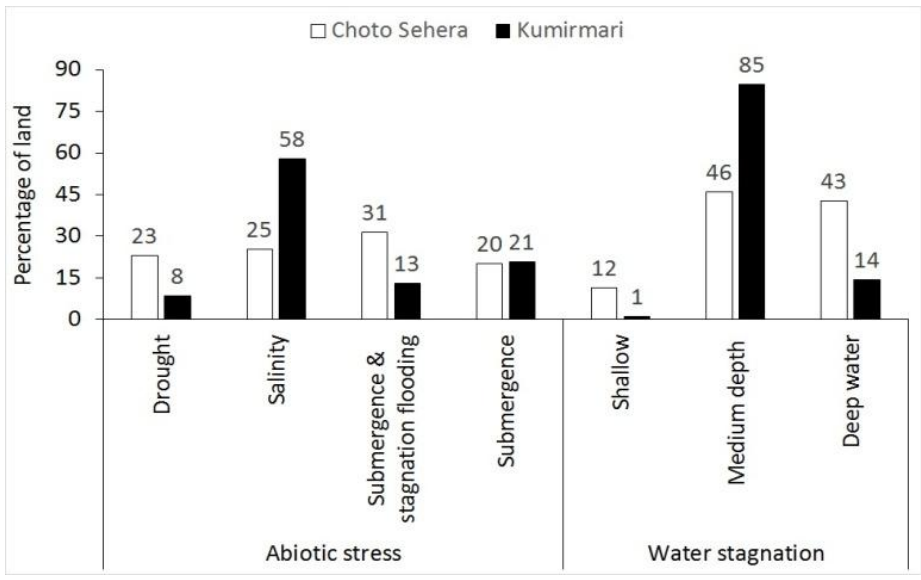

Figure 4. Percentage of lands under the grip of abiotic stresses in two villages of Choto Sehera and Kumirmari.

\section{Performances of stress tolerant rice varieties}

Stress-tolerant varieties produced significantly higher yield as compared to local traditional cultivars (Fig. 5). Luna Sankhi was grown in dry season while all other five varieties were grown at wet season. Savitri-Sub1 produced better yield (5.998 t $\left.\mathrm{ha}^{-1}\right)$, followed by Swarna-Sub1 (5.273 $\left.\mathrm{t} \mathrm{ha}^{-1}\right)$, Varshadhan $\left(5.1777 \mathrm{t} \mathrm{ha}^{-1}\right)$, CR Dhan $406\left(5.159 \mathrm{t} \mathrm{ha}^{-1}\right)$, Luna Sankhi (4.434 $\left.\mathrm{t} \mathrm{ha}^{-1}\right)$ and CR Dhan 403 (4.373 $\left.\mathrm{t} \mathrm{ha}^{-1}\right)$.

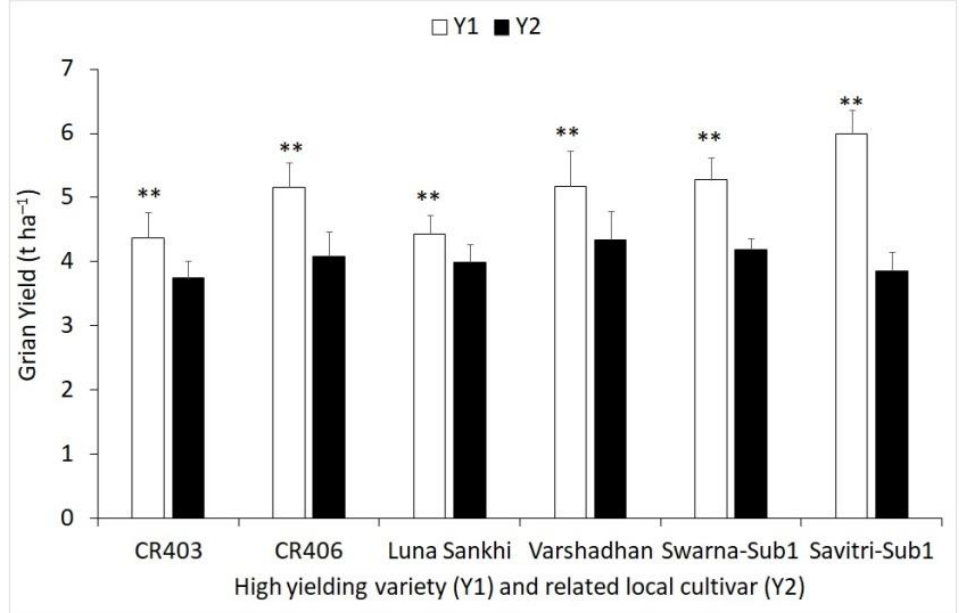

Figure 5. Comparison of yield of stress tolerant high yielding varieties with that of traditional cultivars. **, denotes highly significant differences between high yielding variety and corresponding tested traditional cultivars. CR Dhan 403 was tested against three traditional rice cultivars such as Pankaj, CR1017 and Patnai; CR Dhan 406 against CR1017 and Pankaj; Luna Sankhi against Satabdi and M-Shankar; Varshadhan against Pankaj, Patnai, Sabita, CR1017 and Kalo Mota; Swarna-Sub1 and Savitri-Sub1 against Masuri, CR1017 and Kalo Mota. 


\section{Acceptance of stress tolerant varieties, seed purchase and production}

During wet season the acceptance of stress tolerant cultivars was $98 \%$ whereas during dry season the acceptance was merely 20\% (Fig. 6A). Farmers of nearby locality showed greater interest to purchase the seeds from the farmers who grew these cultivars. One hundred ninety-five $\mathrm{Kg}$ of seeds were sold by the farmers (Fig. 6B). Six hundred forty-five $\mathrm{kg}$ of seeds of four varieties were purchased by the members of two Non-Government Organisations (NGOs) such as Pathar Pratima Dakshin Shibganj Lokosiksha and Rural Development Society and Citizen Forum, Basanti (Fig. 6C). Although the yield advantage of CR Dhan 402 was not significant over checks but it was accepted by a few farmers due to its lesser duration as compared to local varieties. Pathar Pratima Dakshin Shibganj Lokosiksha, a NGO took interest and started to produce seeds of the rice cv. Swarna-Sub1.
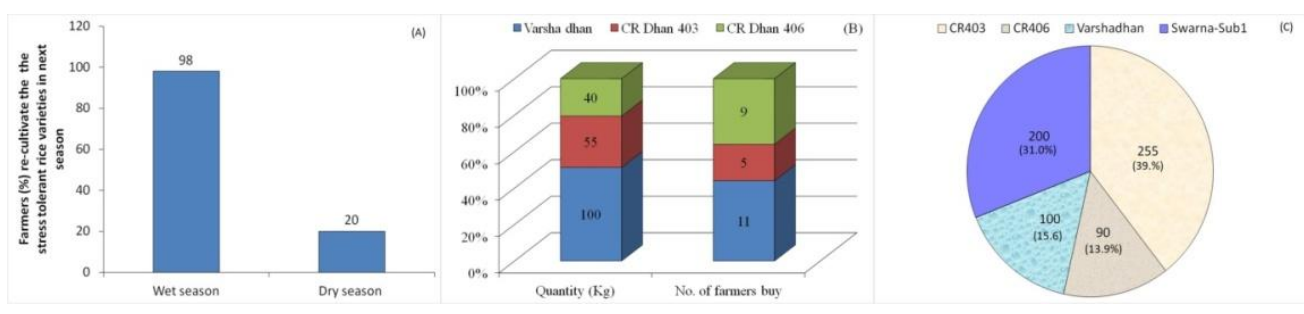

Figure 6. Impact of cultivation of stress tolerant rice varieties in Sundarbans area. (A) Percentage of farmers convinced to re-cultivate the stress tolerant rice during wet and dry season, (B) Numbers of farmers purchased the seeds from other farmers by seeing the performances of stress tolerant rice, (C) Quantities of seeds purchased by farmers from farmers group / NGOs.

\section{Breeder seed indent from Government of West Bengal, India after varietal demonstration}

Since 2015 breeder seed indent of CR Dhan 402, CR Dhan 403, CR Dhan 405, Varshadhan and Savitri-Sub1 by the Agricultural Department, Government of West Bengal, India. The present demonstrations at farmers' fields in Sundarbans had great impact on this initiative (Table 2). 
Table 2. Breeder seed indent (quintal) for varieties under study from West Bengal after varietal demonstration

\begin{tabular}{|c|c|c|c|c|c|c|c|c|}
\hline \multirow{2}{*}{ Varieties } & \multicolumn{6}{|c|}{ Year wise breeder seed indent $(\mathrm{q})$} & \multirow{2}{*}{$\begin{array}{c}\text { Estimated } \\
\text { certified } \\
\text { seed }(\mathrm{q})\end{array}$} & \multirow{2}{*}{$\begin{array}{c}\text { Estimated } \\
\text { number of } \\
\text { farmers }\end{array}$} \\
\hline & 2015 & 2016 & 2017 & 2018 & 2019 & Total & & \\
\hline CR Dhan 402 & 0.5 & 0.2 & 0.3 & 0.5 & 1 & 2.5 & 2000 & 12500 \\
\hline CR Dhan 403 & 0.5 & 0.2 & 0.3 & 0.5 & 1 & 2.5 & 2000 & 12500 \\
\hline Varshadhan & 1 & & 3 & 3 & 3 & 10 & 8000 & 50000 \\
\hline Swarna- Sub1 & 14 & 12 & 31 & 14 & 14 & 85 & 68000 & 425000 \\
\hline Savitri- Sub1 & ------ & 0.5 & 2 & 2 & 2 & 6.5 & 5200 & 32500 \\
\hline \multicolumn{7}{|c|}{ Total } & 85200 & 532500 \\
\hline
\end{tabular}

(Source: https://seednet.gov.in/)

\section{DISCUSSION}

Big natural hazards change the land use pattern and habitat of the people of Sundarbans. During 2009, super cyclone 'Aila' occurred in the month of May; 2.5 million people of 4249 villages were affected in Indian site with approximate loss of property of \$330 million and similar destruction was occurred in Bangladesh site (Saha, 2017). Area of crop cultivation decreased whereas water body increased in 2013. Captive shrimp and fish cultivation took a leading role. A social change occurred. Marginal farmers became landless and started to work as labourer in fishing ponds (Datta and Dev, 2012). Patharpratima block was worst affected due to Aila. Two to three years after Aila the agricultural land in some areas became barren while natural catching of fish and collection of honey from the forest decreased substantially that forced the people to migrate in other parts of the Country. People became refugee in their own country due to environmental disaster (Mallick and Vogt, 2014). Forest resource utilization increased greatly for food and fuel that considerably damaged the mangrove ecology (Rahman et al., 2017). So, cultivation of crops under adverse conditions is necessary not just for food security but for livelihood resiliency of the farming community of Sundarbans as well as for the protection of mangrove ecology.

In two villages among the 99 farmers 91 were marginal types with $<1$ ha of land (Fig. 1). Farmers in BPL category (income Rs. $2250 \approx \$ 32 /$ month) are more vulnerable due to climate change (Ferreira et al., 2015). A little economic gain is a great bonus to poor people. Food insecurity forced them to migrate. They mainly cultivated rice for survival; none of the farmers cultivated rice for commercial purposes (Fig. 1). Even, $39.8 \%$ and $62 \%$ of farmers respectively of the Choto Sehera and Kumirmari did not sale their rice to market. The rest of the farmers though sold their rice to 
market; it was due to unwarranted troubles. Some irrigation facilities were available in both the villages yet all of them depended on rainwater during rainy season. Due to lack of sufficient irrigation facilities during dry season, they were compelled to cultivate rice once in a year. This showed that a chunk of farmers in Sundarbans were helpless (Dasgupta et al., 2016).

Farmers had definite idea about the problems of rice cultivation (Fig. 2). Among the different issues, we addressed mainly on technological issues which were hindering rice cultivation. Farmers of Sundarbans opined that flooding and erratic rainfall greatly hindered rice cultivation. So, the rice varieties that possessed tolerance to different abiotic stresses were asked for by the farmers with acceptable grain type (Fig. 3). Abiotic stresses such as drought, water stagnation, submergence and salinity were predominant at different localities of Sundarbans (Fig. 4). It showed that rice cultivars tolerant to different abiotic stresses were helpful to farmers to produce more as compared to cultivars which lacked stress tolerance character. Farmers of Sundarbans grew large numbers of rice cultivars, which were either traditional type (e.g. Kala Mota, Patnai, Sabita) or high yielding type released long back in 1970's (e.g. CR 1017 and Pankaj) or 1960s's (e.g. SR26B). Earlier attempts were made to introduce modern high yielding rice cultivars but no success was achieved due to lack of stress tolerance characters of those varieties (Dar et al., 2017). Yield advantage of newly improved stress tolerant rice cultivars was $0.44,0.63,0.84,1.07,1.08$, and $2.14 \mathrm{t} \mathrm{ha}^{-1}$ respectively, in Luna Sankhi, CR Dhan 403, Varshadhan, CR Dhan 406, Swarna-Sub1 and Savitri-Sub1 (Fig. 5). In India, presently the minimum support price (MSP) of rice is ₹ 1750 or $\$ 25 \mathrm{q}^{-1}(100 \mathrm{Kg}=1$ quintal $(\mathrm{q})=0.1$ tonnes $(\mathrm{t}), \$ 1$ = ₹ 70). Farmers could earn ₹ $7700-37450$ or $\$ 110-535$ ha $^{-1}$ extra compared to the old cultivars.

Due to unavailability of seeds of high yielding stress tolerant varieties farmers of these areas were in compulsion for cultivation of local /old rice varieties. It showed that to access seed of good varieties by the marginal and small farmers through formal seed supply agencies was a non-starter. The present investigation showed that the situations had been changed in study area. Farmers started to cultivate stress tolerant cultivars instead of local cultivars (Fig. 6). Seeds produced locally were accepted by the farmers very easily as they observed the goodness of such varieties by themselves or hearing from neighbours (Wossen et al., 2017). Cultivars grew in wet season were highly accepted by the farmers. During dry season though Luna Sankhi (Fig. 5) gave better yield as compared to locally available two cultivars such as Satabdi and M-Shankar, yet Luna Sankhi was not so popular among the farmers due to bold type grain quality. The purpose of rice cultivation during dry season was to sell in market rather than home consumption (Fig. 6A). It was observed that involving local agricultural Government Officials was useful to extend benefit to farmers. Government of West Bengal, India started to give indent of breeder seeds to national seed supplying authorities (Table 2). The indented breeder seeds could produce 86,000 quintal of certified seeds. In India, generally, certified seeds are used in cultivation. Certified seeds are sold through Government machinery to the farmers 
in a small packet suitable for 1 acre $(0.4$ ha) of land. If a farmer cultivates stress tolerant varieties in 1 acre $(0.4 \mathrm{ha})$ of land, then the numbers of beneficiaries were estimated to be more than 0.5 million (Table 2). Involving formal seed supply agencies fasten the seed distribution, however, there were always hurdle whether such seeds would be accessible to small and marginal farmers or not. Big farmers with resources can snatch the benefit from small and marginal farmers. Here is the importance of informal seed supply (Sperling and McGuire, 2010). Informal seed systems had better promise to supply the seeds to weak and poor farmers. Besides farmers to farmers seed supply, NGOs played a crucial role in this respect.

\section{CONCLUSION}

Sundarbans- a highly popular place where rice is mainly grown during the rainy season. Most of the farmers are poor. Improving rice productivity is directly helpful to these people to secure food, employment and overall social security. Improving knowledge to grow stress tolerant varieties of farmers is essential to mitigate their drudgery. Growing stress tolerant rice varieties, farmers could get 0.44 to $2.14 \mathrm{t} \mathrm{ha}^{-1}$ more yield than traditional cultivars even under various abiotic stresses such as salinity, submergence and stagnant flooding. So, stress tolerant rice is an armoury to fight against insecurity to food and livelihood. Additional produce of rice would reduce the dependence of poor and marginal farmers on forest. Little financial goodness to poor people has great consequence on society in relation to education and health. Seeds produced locally were most acceptable to small and marginal farmers and were more accessible to them. Seed production at village level would be more useful to small and marginal farmers.

\section{ACKNOWLEDGEMENT}

Authors are grateful to Indian Council of Agricultural Research, New Delhi for funding under National Innovations of Climate Resilient Agriculture and Emeritus Scientist Project.

\section{REFERENCES}

Aziz, A. and Paul, A.R. (2015). Bangladesh Sundarbans: Present status of the environment and biota. Diversity, 7(3): 242-269.

Bastakoti, R.C., Gupta, J., Babel, M.S. and van Dijk, M.P. (2014). Climate risks and adaptation strategies in the lower Mekong river basin. Regional Environmental Change, 14(1): 207-219.

Dar, M.H., Chakravorty, R., Waza, S.A., Sharma, M., Zaidi, N.W., Singh, A.N., Singh, U.S. and Ismail, A. (2017). Transforming rice cultivation in flood prone coastal Odisha to ensure food and economic security. Food Security, 9(4): 711-722.

Dasgupta, S., Hossain, M.M., Huq, M. and Wheeler. D. (2016). Facing the hungry tide: Climate change, livelihood threats, and household responses in coastal Bangladesh. Climate Change Economics, 7(3): doi.org/10.1142/S201000781650007X 
Datta, D. and Dev, S. (2012). Analysis of coastal land use/land cover changes in the Indian Sunderbans using remotely sensed data. Geo-spatial Information Science, 15(4): 241250.

Ferreira, F.H.G., Chen, S., Dabalen, A., Dikhanov, Y., Hamadeh, N., Jolliffe, D., Narayan, A., Prydz, E.B., Revenga, A., Sangraula, P., Serajuddin, U. and Yoshida, N. (2015). A Global Count of the Extreme Poor in 2012: Data Issues, Methodology and Initial Results. Policy Research Working Paper 7432, World Bang Group. http://econ.worldbank.org

Ghosh, A., Schmidt, S., Fickert, T. and Nüsser, M. (2015). The Indian Sundarban mangrove forests: History, utilization, conservation strategies and local perception. Diversity, 7(2): 149-169.

Kanda, Y. (2013). Investigation of the freely available easy-to-use software 'EZR' for medical statistics. Bone marrow transplantation, 48(3): 452-458.

Mallick, B. and Vogt, J. (2014). Population displacement after cyclone and its consequences: empirical evidence from coastal Bangladesh. Natural Hazards, 73(2): 191-212.

Rahman, M.M., Rahman, M.M., Shahid, S., Khan, R.U., Jahan, N., Ahmed, Z.U., Khanum, R., Ahmed, M.F. and Mohsenipour, M. (2017). The impact of cyclone Aila on the Sundarbans forest ecosystems. International Journal of Ecology and Development, 32(1): 87-97.

Saha, S.K. (2017). Cyclone Aila, livelihood stress, and migration: empirical evidence from coastal Bangladesh. Disasters, 41, 505-526.

Sarkar, R.K. and Ray, A. (2016). Submergence-tolerant rice withstands complete submergence even in saline water: Probing through chlorophyll a fluorescence induction O-J-I-P transients. Photosynthetica, 54(2): 275-287.

Sperling, L. and McGuire, S. (2010). Understanding and strengthening informal seed markets. Experimental Agriculture, 46(2): 119-136.

Wossen, T., Abdoulaye, T., Alene, A., Haile, M.G., Feleke, S., Olanrewaju, A. and Manyong, V. (2017). Impacts of extension access and cooperative membership on technology adoption and household welfare. Journal of Rural Studies, 54: 223-233.

Yu, D., Peat, G., Bedson, J., Edwards, J.J., Turkiewicz, A. and Jordan, K.P. (2016). Weighted cumulative exposure models helped identify an association between early knee-pain consultations and future knee OA diagnosis. Journal of Clinical Epidemiology, 76: 218-228. 